
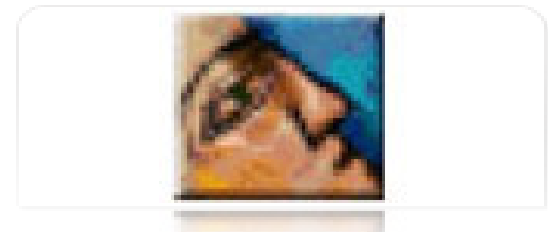

\author{
Diálogos Revista Electrónica de Historia \\ E-ISSN: 1409-469X \\ historia@fcs.ucr.ac.cr \\ Universidad de Costa Rica \\ Costa Rica
}

Cabezas Bolaños, Esteban

La descripción archivística y su aplicación en documentos particulares: el caso del Album de Figueroa

Diálogos Revista Electrónica de Historia, vol. 1, núm. 2, enero-marzo, 2000, p. 0

Universidad de Costa Rica

San Pedro de Montes de Oca, Costa Rica

Disponible en: http://www.redalyc.org/articulo.oa?id=43910207

Cómo citar el artículo

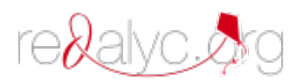

- Número completo

- Más información del artículo

Página de la revista en redalyc.org

Sistema de Información Científica

Red de Revistas Científicas de América Latina, el Caribe, España y Portugal

Proyecto académico sin fines de lucro, desarrollado bajo la iniciativa de acceso abierto 


\section{La descripción archivística y su aplicación en documentos particulares: el caso del Album de Figueroa}

\section{Esteban Cabezas Bolaños}

El proceso de descripción es un conjunto de principios y técnicas que se han desarrollado en los últimos 100 años para ser aplicadas en diferentes fondos documentales de origen público, privado y particular. Al respecto Fredric Miller comenta que la descripción es un proceso "... firmemente enraizado en la peculiar naturaleza del material archivístico y en la secuencia lógica del quehacer de los archivos".

De manera que la descripción abarca una gama amplia de espacios y se vale de un gran número de instrumentos que llevan como único fin el orientar al usuario para que pueda aprovechar el material archivístico.

El presente artículo expondrá los postulados teóricos de la descripción documental y su aplicación en un documento de origen particular custodiado por el Archivo Nacional de Costa Rica, conocido como Album de Figueroa, en donde emplearemos los principales postulados archivísticos dentro del campo para crear un instrumento descriptivo que facilite al usuario el localizar la información que busca o necesite.

La descripción documental

La descripción es una actividad archivística que debe ser realizada en forma conjunta a la ordenación con el fin de ayudar en la consulta tanto a usuarios externos como a la administración productora y para facilitar al archivista el control y administración de la documentación.

Podemos definir descripción como aquel proceso que busca transmitir la información y los rasgos más sobresalientes presentes en un documento a través de una idea general, producto del análisis y la síntesis, que nos permitirá ver sus partes o propiedades por medio de palabras y términos normalizados.

De esta manera el archivista, al iniciar el proceso de descripción en un fondo documental, debe seguir ciertos pasos esenciales, como la recolección del material, su debida clasificación, y un análisis que permita determinar tanto su valor archivístico como su origen.

Estos pasos son importantes porque nos permiten conocer el documento y la institución productora y a la vez determinar las características internas y externas 
más sobresalientes, las cuales son indispensables para una buena descripción de las series documentales.

Una vez realizado este análisis se debe trasladar la información contenida en los documentos a un sistema descriptivo global, que sea sencillo y de fácil manejo, para que el usuario pueda tener una noción clara del origen del documento, su contexto, procedencia, clase y tipo documental, contenido, formato, soporte y los modos en que puede recuperarse y ser consultado.

Finalmente estos sistemas descriptivos deben ser publicados y sujetos a un programa de difusión amplio a través de revistas especializadas o bien por medio de su distribución a usuarios potenciales, archivos o bibliotecas que nos sirvan de referencia.

Por lo tanto es importante que todos los archivos desarrollen un Programa Descriptivo, o sea, una política institucional, fundamentado en normas nacionales o internacionales que planteen un procedimiento homogéneo para la síntesis de cada unidad documental, de manera que se le facilite al usuario el acceso a la documentación custodiada. El programa descriptivo consistirá en normas que serán diseñadas dependiendo del contenido del fondo documental y la capacidad y disponibilidad del archivista.

Para realizar un programa descriptivo debemos tomar en cuenta cuatro elementos fundamentales:

1. la descripción de los documentos debe ser concreta, breve y contener las ideas básicas,

2. se deben describir factores internos y externos,

3. se adoptará una sola política descriptiva para todo el fondo y,

4. se desarrollará el sistema descriptivo de manera que el usuario pueda buscar por sí solo la información (ficheros, bases de datos, catálogos, etc...) sin depender del archivista.

Lo anterior es alcanzado por el archivista a través de distintos instrumentos descriptivos como guías, inventarios, índices y catálogos. Estos instrumentos tienen una doble misión que consiste en crear un contexto que permita orientar al usuario que ingresa por primera vez a un archivo y facilita la búsqueda a los que ya lo conocen, además permiten al archivista conocer el contenido, cantidad y series que custodia, además de su localización en el espacio físico. 
Las guías nos permiten describir el fondo a nivel general reflejando sus secciones y temáticas, facilitando información como procedencia, origen funcional, fechas extremas, formatos, volumen, formas e indicando el contenido de las series.

Los inventarios son instrumentos que se levantan una vez que la documentación esta organizada y ordenada, en ellos se incluyen la procedencia, el origen funcional, la clase y tipo documental, las fechas, formatos, volumen, además de una descripción que puede ser a nivel de fondo, serie, o pieza documental cuyo detalle queda sujeto a la disposición del archivista. Su principal función es evidenciar la existencia o ausencia de un documento, además permite realizar recuentos del fondo y garantizar la permanencia y recuperación fácil de la organización natural de los documentos a través de la signatura topográfica.

El índice es un instrumento que brinda información en forma extensiva la cual nos permite localizar diversos datos de tipo geográfico, onomástico, o cronológicos entre otros. Este instrumento le permite al usuario localizar en forma directa por medio de palabras de personas, lugares o temas que lo remitirá a una signatura topográfica.

Por último se encuentran los catálogos que ponen su atención en el contenido del documento a un alto nivel de detalle, centrándose en la procedencia, fechas, lugares, personas y asuntos que figuren en él. En este instrumento la descripción es pieza por pieza, con información substancial exhaustiva, tanto de sus caracteres internos como externos.

Otro instrumento que esta ganado mucha aceptación en el campo archivístico costarricense es la Lista de Remisión, por ser un instrumento muy sencillo el cual proporciona información concreta, junto a una fácil adaptabilidad a cualquier tipo de archivo. Se compone de un número de orden que indica la cantidad de documentos custodiados por una serie, la signatura que lo ubica en el espacio físico, una casilla para contenido en donde se anota un resumen del documento, otra casilla para anotar las fechas extremas y finalmente una en donde se indica el número de folios.

La Lista de Remisión tiene la gran ventaja de ser modificada de acuerdo a las necesidades del fondo o con aquellas características que el archivista desea manifestar.

Otro instrumento descriptivo que ha surgido a nivel mundial es la Norma Internacional General de Descripción Archivística ISAD (G), la cual consiste en un conjunto de reglas generales encaminadas a asegurar la creación de descriptores coherentes, apropiados e inteligibles por sí mismas. También 
pretende facilitar la recuperación y el intercambio de información entre archivos, normalizar los encabezamientos autorizados y posibilitar la integración de descriptores de diferentes archivos en un sistema unificado de información.

La idea de emplear esta norma es que pueda ser aplicada a las descripciones de documentos sin tomar en cuenta la naturaleza o volumen de la unidad de descripción con el fin de constituir la descripción de cualquier unidad a través de varios niveles de manera que se represente el fondo desde lo mas general a lo específico informándonos bajo que circunstancias surgen los documentos y en forma muy general cual es el tipo documental que generó.

La ISAD-G es en la actualidad uno de los instrumentos descriptivos más recomendados por los organismos internacionales, cuyo objetivo básico es proveer un medio que nos indique cual es la institución productora, bajo que contexto surge, que tipos de documentales produce y proveernos de una visión general de la institución para finalmente referirnos a cada tipo documental a nivel de unidad.

En la medida en que alcancemos un grado de detalle en la descripción de los fondos aumentaremos la consulta de nuestros archivos, porque el usuario al ver la facilidad con que accede a la documentación consultará más el archivo y con base en su información generará conocimiento y tomará decisiones.

Debe quedar claro la importancia de esta actividad archivística dentro de nuestro quehacer profesional porque consideramos que un archivo está vivo en la medida en que sea consultado y para que ello ocurra deben existir instrumentos descriptivos que orienten e informen a los usuarios el contenido de la información almacenada en nuestros depósitos.

La descripción en documentos particulares

La documentación de origen particular forma parte de los archivos por que son creados o reunidos por una organización o individuo en el ejercicio de sus funciones o como producto de su creatividad, y el cual fue transferido a un archivo para su conservación permanente por su valor histórico.

Tomando en cuenta esta definición y los criterios de descripción anotados en líneas anteriores, en julio de 1999, el archivero Jorge Jiménez Espinoza y este autor realizaron la descripción de un documento de origen particular conocido como Album de Figueroa. 
Dicho documento es uno de los grandes legados culturales, históricos y artísticos heredados del siglo XIX, elaborado y redactado por José María Figueroa Oreamuno. Este documento es uno de los primeros intentos por interpretar la historia patria, ilustrado hábilmente con hermosos dibujos en donde se reflejan diversos acontecimientos históricos, costumbres, tradiciones y rasgos culturales de Costa Rica desde el período colonial hasta fines del siglo XIX.

En este documento la información se encuentra en diferentes formatos desde la clase textual con manuscritos e impresos, hasta mapas, dibujos, fotografías, transcripciones de documentos, recortes de periódicos y revistas, con los cuales el autor reconstruye las diferentes escenas del período colonial y republicano, dando por evidencia la evolución de nuestra sociedad.

De igual manera, incorpora en su álbum trabajos e investigaciones elaboradas por otros investigadores y exploradores en los cuales también incluye análisis y comentarios propios.

Una de las características más sobresalientes del Album de Figueroa fue la forma en que su autor introdujo la información en el soporte, debido a la gran dimensión que poseen sus folios, la gran cantidad de manuscritos y dibujos, y la exhaustiva labor que significó el elaborar y recolectar la gran diversidad de documentos anexos al álbum.

Don José María no elaboró un índice de su obra por lo cual resulta difícil para cualquier usuario poder localizar la información. Con el fin de solucionar esta necesidad el Archivo Nacional creo un instrumento en enero de 1918 el cual contiene una breve descripción del documento, la cual se torna escueta al no tomar en cuenta los diferentes tipos documentales y por consiguiente la información completa que se expresa en cada uno de sus folios. Ejemplo de esto son las genealogías descritas de la siguiente forma:

"... páginas 291 a 376. Arbol genealógico de las principales familias de Costa Rica..."

En esta descripción se desconoce de que familia trata cada genealogía y los lugares de donde proceden. Estos datos se encuentran expresados en cada folio al tratarse de familias de diversos lugares como Heredia, Alajuela y Cartago, entre otros. 
Otro caso se puede observar en la página 7 de dicho instrumento, la cual es descrita como "... copia de documentos para la historia de Costa Rica", pero que en realidad contiene narraciones sobre las incursiones de Francis Drake en Centroamérica y la transcripción de una carta de Francisco Zárate al Virrey de Nueva España Martín Enríquez con fecha de 1579.

Debido a que esta descripción no brinda toda la información que el usuario pueda demandar, y más bien los datos que contiene son irrelevantes y aislados del contexto del álbum y, además las características tan diversas presentes en un solo documento, elaboramos una estrategia de descripción de manera que pudiéramos brindar al usuario potencial la información que requiere y a la vez ubicarlo en el contexto histórico y personal que le dio origen.

Para cumplir esta meta se creo un nuevo índice (Ver Cuadro 1) en el cual se han incluido los datos dividiendo la información en tres casillas: folio, contenido y observaciones.

La casilla de folio se baso en la foliación que indicaba las diapositivas elaboradas en España cuando este fue llevado para su restauración. Se utilizaron estas fotografías para su descripción por encontrarse el documento totalmente desarmado y en proceso de restauración en el departamento de conservación del Archivo Nacional. Esta casilla reemplaza el número de signatura que nos ayuda a localizar cualquier documento o caja en un depósito.

Debemos tomar en cuenta que el documento fue encuadernado en dos tomos y en sus hojas es donde se encuentra plasmada toda la información, de manera que su localización se debe hacer a través de un instrumento descriptivo que a nivel de folio.

En la casilla de contenido se efectuó una descripción detallada de cada uno de los tipos documentales y la información en general que contenía cada folio, en el cual además se incluyeron sus fechas extremas.

Por último en las observaciones se detallan las clases de los documentos descritos; es decir si son manuscritos, dibujos, fotografías, mapas o planos, con el fin de indicarle al usuario el tipo de soporte en que esta dispuesta la información en el documento.

Consideramos que esta descripción es la más beneficiosa tanto para el usuario como para los encargados de este documento en el departamento Archivo Histórico del Archivo Nacional. 
Además, como se indicó en líneas anteriores, una de las misiones más importantes del archivista es divulgar los instrumentos descriptivos, nosotros además de cumplir con este objetivo pretendemos dar un tributo al gran artista que fue José María Figueroa Oreamuno y su genial obra a través del catálogo que elaboramos y que será publicado en la Revista del Archivo Nacional en su número del año 2000 en homenaje al centenario de su fallecimiento.

\section{Cuadro 1}

\begin{tabular}{|c|c|}
\hline & TOMO I \\
\hline o & $\begin{array}{l}\text { Texto introductorio en el que se refiere a sus principales viajes y } \\
\text { colaboradores en la creación del álbum. } \\
\text { Escudo del Ducado de Veragua, bandera de Cristóbal Colón y retratos de Jose } \\
\text { María Figueroa, la Reina Isabel, Manuel María Peralta, Guillermo Willin, } \\
\text { Vázquez de Coronado y dos indígenas. }\end{array}$ \\
\hline $\mathbf{1 F}$ & $\begin{array}{l}\text { Plano de Terraba y Boruca levantado por el colombiano Francisco González } \\
\text { Cáceres. } \\
\text { Relato sobre la expedición de Francisco González Cáceres a Terraba. }\end{array}$ \\
\hline $1 \mathrm{~V}$ & $\begin{array}{l}\text { Mapa de la costa de la Mosquítia. } \\
\text { Descripción de las costumbres de los Zambos Mosquitos. }\end{array}$ \\
\hline $2 F$ & $\begin{array}{l}\text { Real Cédula de } 1565 \text { en que se le agradece a la ciudad de Cartago sus } \\
\text { servicios y se le concede su escudo de armas. } \\
\text { Lista de los pueblos indígenas de Talamanca y la costa del norte, poblados y } \\
\text { los conquistadores de Costa Rica. } \\
\text { Autos de Repartimiento de indios en encomienda, hechos por Perafán de } \\
\text { Rivera. } \\
\text { Escudo de armas de Cartago. }\end{array}$ \\
\hline $2 \mathrm{~V}$ & $\begin{array}{l}\text { Continuación de autos de repartición de indígenas por encomiendas. } \\
\text { Narraciones de las incursiones de Francis Drake en Centroamérica. }\end{array}$ \\
\hline
\end{tabular}




\begin{tabular}{|c|l|}
\hline 3F & $\begin{array}{l}\text { Continuación de Narraciones de Francis Drake. } \\
\text { Carta de Francisco Zarate a Martín Enríquez Virrey de Nueva España el } 16 \text { de } \\
\text { abril de 1579. }\end{array}$ \\
\hline $\mathbf{3 V}$ & Narración del autor sobre la invasión de Francis Drake a Costa Rica \\
\hline $\mathbf{4 F}$ & $\begin{array}{l}\text { Ataques de Francis Drake a los puertos del Callado, Cabo Verde y Costa } \\
\text { Rica; y encuentro de este con Francisco de Zarate en la Costa de Guatemala. }\end{array}$ \\
\hline
\end{tabular}

Bibliografía

Cortéz Alonso, Vicenta. 1991. Necesidad y Condiciones de un programa descriptivo de archivos en nuestros días. En: Archivística, Cesar Gutiérres compilador, Pontificia Universidad Católica del Perú. Lima, Perú.

Cuadernillos del Archivísta. 1997. Norma Internacional General de Descripción Archivística, ISAD-G. Archivo General de la Nación, Mexico.

Jiménez, Jorge y Cabezas, Esteban. 1999. El Album de Figueroa: una pieza única al servicio de la investigación. Ponencia presentada en la II Jornada de Investigación de la Vicerrectoría de Investigación, Universidad de Costa Rica .

Miller, Fredic. 1994. Ordenación y Descripción de Archivos y Manuscritos. Sociedad de Archivístas Americanos, OEA.

Romero, Manuel. 1997. Archivística y Archivos: soportes, edificios y organización. 3 edición $\mathrm{S}$ y $\mathrm{C}$ ediciones. Carmona, España. 